\title{
EDITORIAL
}

\section{Should Intellectual Property Rights influence the Development of a Research Strategy?}

There is much less investment in basic research today although high profile basic research is still funded by the leading economies. Basic research receives very little funding in developing countries and researchers seeking funding for basic research know that they can only succeed if it is showcased as having some element of application. What is often forgotten is that applied research relies on knowledge from basic research in order to surmount any research roadblocks it faces. If that knowledge is not readily available, researchers will be forced to go back into basic research when they face mind-boggling problems which hinder progress towards their "applied" target.

Decision makers in science in most developing countries are faced with the dilemma as to whether research in basic science should be supported. The limited resources available for science it is claimed would be better used on research which provide tangible benefits to the country. This is particularly true for countries like Sri Lanka which hold reasonably fair regular elections making it imperative for governments to fund projects which produce electorally popular outcomes in the short-term. Unfortunately scientific research falls short of this category. It is therefore hardly surprising that government expenditure on research and development (GERD) in many developing countries is low, with Sri Lanka's GERD hovering around $0.11 \%$ of GDP during the past decade placing it within the bottom one-tenth of the world in research expenditure.

Sri Lanka therefore allocates insignificant funds for research projects, a few of them in the order of Rs 50 million (USD 260,000) but most about a tenth of this amount and that too channelled almost exclusively into projects in "applied" research. While providing such insignificant amounts for research, our politicians and administrators reiterate their beliefs that patents, licencing and royalty payments should ensue from research significantly contributing to the national economy and constantly blame scientists for their inability to produce such outcomes.

The reason for this feeling is not far to seek as the World Trade Organization (WTO) and globalization pundits consistently parade the importance of incorporating private sector values into research. The high investments made by international business in research and development (R \& D) today is made with an eye on developing strong intellectual property rights (IPR) protection which would ensure profitability. Pharmaceutical companies often tout a figure of USD 1 billion as the cost of developing a marketable drug, but even if it is half that sum, that would be more than double Sri Lanka's total expenditure on all areas R \& D. Most developing countries with their low investments in research have neither the infrastructure nor the human resources for high level research. The weak private sector in these countries carry out research if at all only when state subsidies and incentives are provided. Public Private Partnership models of research in developing countries inevitably lead to ever-increasing demands for continuous public sector investment while retaining tight private sector control. Although state funded research has made some progress in India, China and the US, the models they have respectively promoted for commercialization such as contract research, political support for researchers to start their own business and the Bayh-Dole Act have not been totally satisfactory.

The often quoted Korean and Taiwan examples are irrelevant today as import controls, export subsidies, selective foreign direct investment, discriminatory IPR laws, low waged labour and unrestricted reverse engineering which they employed are no longer possible under WTO rules..

In today's world, the private sector and even the state concentrate on funding in research areas with a potential for profitable outcomes through exploitation of IPR. Such research strategies therefore lead to large areas of ignorance - areas of research with no potential for IPR or profit where no investment is made. As we continue to concentrate only on applied research, we sometimes do not even know the areas where we lack knowledge falling into an ignorance of ignorance trap. Furthermore, the focus of funding being on potential for profit means that many areas of public welfare research like environmental safety and low-cost initiatives in areas like housing and health cannot find funding and are neglected.

Since the present direction of research is towards profit, there is little room for curiosity based problem solving as most research is orientted towards obtaining patentable products. This also means that there is less funding available for research in important fields like social science unless they are in business allied areas like market research. The worldwide trend has been for private funding with its profit seeking outlook to increase while state funding is in decline. Since patenting is focussed on commercialization and generating royalties, business plans, market research and commercial law have now become important components of scientific research. There is less dissemination of knowledge in the early stages of research as research proposals, plans and results are kept confidential, unpublished and made freely available only when it is clear that no commercial potential exists.

Apart from problems due to low investment in research 
and development, commercializing research in developing countries like Sri Lanka is mired with many challenges. We are unable to produce sufficient $\mathrm{PhD} / \mathrm{MPhil}$ qualified researchers and the few research graduates produced come from a pool of average performers rather than the cream of their students. The best high school students go in for medicine, mostly ending up in medical practice rather than research while the top students graduating in science and engineering move almost immediately to the US intending to complete their graduate studies but ultimately end up as permanent settlers. With low funding, scientific infrastructure for R\&D is lacking so that laboratories are ill equipped and mechanisms for maintenance and replacement are absent or inefficient. Intermediary institutions that encourage commercialization of research like science parks and business incubators are often unavailable while the same is true of a vibrant IPR culture. Research in these countries while contributing to the training of research scientists cannot therefore be really be expected to lead to successful commercialization.

This is confirmed by US Patent Office (USPO) data which shows that less than $10 \%$ of developing countries were able to obtain an average of 20 US patents/year. Many of them were semi-industrialized developing countries or developing countries with research units of Western companies. India, Singapore, China, Malaysia and Thailand respectively for instance had an annual average USPO patent count of 3340, 945, 860, 260 and 92 for the 2013-2017 period compared with figures for Pakistan, Sri Lanka and Bangladesh of 15, 4.8 and 3.

Although patenting by academic institutions in the US has been promoted by the Bayh-Dole Act of 1980 sanctioning private commercialization of US government funded research, less than a third of the patents granted to Universities have been licensed and even less commercialized. Most Universities earned from IPR less than the money spent on their technology transfer offices and very few recovered the money spent on research. Stanford University which averaged 350 patents a year, much more than most developing countries, invested around USD 700 million on research in 2007 but its licensing income from 987 licences was only $\$ 50 \mathrm{~m}$ that year. Of 8000 invention disclosures made since 1970, half were patented and a quarter licensed but Stanford earned royalties exceeding USD 1 million from only from $1 \%$ of them. It has been estimated that academic research in the US recovers 3\% of research costs through IPR, compared with a world average of $1.7 \%$. Recovery of research expenditure has been possible only in rare instances, usually through a small molecule patent sale for a substantial sum to pharmaceutical industry. Such one-off earnings are rare and far between. There were four recent instances, the HIV drug, Emtricitabine which earned USD 540 m for Emory University in 2005, Remicade, for rheumatoid arthritis which made USD $794 \mathrm{~m}$ in 2007 and over USD 1 billion in total for New York University, the epilepsy drug, pregabalin earning USD $700 \mathrm{~m}$ for North Western in 2007 and the prostate cancer drug, enzalutamide USD 1.14 billion for UCLA in 2016.

While income from technology transfer for most well- funded US Universities are insufficient even to meet their technology office costs, it is surprising to note that developing country politicians and administrators continue to believe that IPR in most research projects would provide substantial returns. This has the effect of putting pressure on scientists to aggressively pursue IPR often creating mistrust not only between scientists but also with industrialists and regulators, the end result often being a hindering of research.

Politicians and administrators in developing countries believe myths that all research will generate patents leading to commercialization although it is clear this is not true even for US institutions. However nurturing this myth is in the interests of developing country science and scientists as it serves to ensure at least that the sparse support for research is continued. The fact though is that very few patents earn money but on the rare occasion that a technology has a foreseeable topical demand and this potential is understood by a multinational corporation, there is a small chance of hitting the jackpot.

The granting of local patents in Sri Lanka is a long drawn out procedure and such patents rarely attract potential investors. Costs of patenting in the US are however high compared with developing country incomes and the decision as to whether to spend such money is often a difficult one, particularly since most patents will not earn enough to recover patenting costs.

There is an alternative to IPR and that is to place all new knowledge in the public domain without patenting it. This used to be the situation for developing country research and for US Federal Government funded research before the Bayh-Dole Act and WTO. Since earnings from commercialization of low technology developing country research are negligible, the social benefits from placing it in the public domain should be considered. There has been no realistic assessment made of this alternative although there is evidence in the past that domestic innovation is facilitated by new knowledge placed in the public domain by state institutions.

Vijaya Kumar

Email:vkumar155@yahoo.co.uk 